\title{
Molecular Genetic Markers and Biochemical Detection between Two Capparis sp.
}

\author{
A.H. Hassan and Esraa A. El Sherbeny \\ Genetics Resources Department, Desert Research Center, Cairo, Egypt
}

\begin{abstract}
This investigation was carried out to assess the relationships between two Capparis sp. (Capparis cartilaginea and Capparis spinosa). Molecular markers Random amplified polymorphic DNA (RAPD) and the inter-simple sequences repeat (ISSR) markers technique were used to determine the genetic relationships between two Capparis sp. The results suggest that a RAPD marker is the best choice for the evaluation of diversity and the genetic relationships between two Capparis sp. with high accuracy which revealed 183 band DNA bands detected across sixteen primers with high polymorphism than ISSR which revealed 76 DNA bands. The genetic relationship among eight genotypes of two Capparis sp. based on biochemical and molecular data developed using dendrogram constructed by UPGMA cluster Conservationist may use the information of the present study to make effective decisions regarding the global protection and management of two Capparis sp. in Egypt.
\end{abstract}

Keywords: Capparis sp.; genetic relationships; SDS PAGE; RAPD-PCR; ISSR; UPGMA.

\section{Introduction}

Family Capparaceae comprises 39 genera and 650 species distributed through warm regions (Boulos 2009). The following popper user interface control may not be accessible. The genus Capparis comprises 250 species including shrubs, trees and woody clmbers. This genus is represented in Egypt by six species (Täckholm V 1974). Discords recommended the use of the leaves and roots of Capparis spinosa $\mathrm{L}$. to reduce swelling and calm the pain of teeth (Gunther 1959). In the Arabian folk medicine, several Capparis sp. have many uses. The total herb of Capparis cartilaginea Decne. is used for bruises, childbirth, earache, headache, paralysis, snakebite and swelling. Also the fruits of Capparis decidua (Forssk.) Edgew are used to relieve difficult breathing as a laxative, anthelimintic and for nervous disorders. Furthermore, the leaves of Capparis spinosa are used for treating earache, coughs, expelling stomach worms and for diabetes (Shahina 1994).

Capparis spinosa is a wild and cultivated bush which grows mainly in the Mediterranean countries. Caper shrubs are generally well adapted to dry areas receiving less than $200 \mathrm{~mm}$ rainfall annually, as most economically important commercial crops cannot be grown under such conditions with-out irrigation, therefore caper shrubs are good candidates for cultivation (Vidaeus 2002). Many countries have given recently greater attention to caper plant, by listing at least one of the Capparis sp. on their research program. IPGRI mentioned caper as a wild species with high economic potential both as aromatic plant and as a vegetable (IPGRI 2001).

On the other hand the International Center for Agricultural Research in the Dry Areas (ICARDA) also considered caper as a medicinal plant that can fill in a gap in the domestic needs of folk medicine and the pharmaceutical industry in their new proposal (Abou Hadid et al.2004).

Molecular markers have been used to determine to be useful for the diversity assessment in a number of wild plant species (waugh and powell, 1992). These markers, based on the polymerase chain reaction (PCR) technique, are the most commonly used for these purposes, several different PCR- based techniques have been developed during the last decade, each with specific advantages and disadvantages. The first example randomly amplified polymorphic DNA (RAPD) markers technique is quick, easy and requires no prior sequence information, which detects nucleotide sequence polymorphisms using a single primer of arbitary nucleotide sequence (Williams et al., 1993 and Abdel-Mawgood et al., 2006).

The second example technique is Inter-simple sequence repeat (ISSR) markers which permit detection of polymorphisms in inter- microsatellite loci, using a primer designed from dinucleotide or trinucleotide simple sequence repeats. ISSR amplifies inter-microsatellite sequences at multiple loci throughout the genome (Li and Xia, 2005)

In the current study the isolation and identification of Molecular genetic markers and biochemical fingerprint between two Capparis sp. and studding the diversity to determine the percentage of genetic similarity of them. 


\section{Plant materials}

\section{Materials And Methods}

Two species for Capparis ( $C$. cartilaginea and $C$. spinosa) were collected from five different ecogeographical localities of the natural habitat in North and South Sinai, Saint Catherine and Red sea coast (Elba Mountain) and conserved in Egyptian desert GenBank in Egypt.

\section{Biochemical genetic analysis (SDS - PAGE)}

Sodium dodeyl sulfate polyacrylamid gel electrophoresis (SDS - PAGE) technique was used to compare among the studied species from different sites by comparing among poly peptide chains protein patterns from seeds and leaves which indicated the gene expressions in plant samples. SDS polyacrylamide gel $15 \%$ was prepared according to the method of Laemmli (1970).

\section{Genomic DNA isolation}

Extraction of total DNA was performed using methods for medicinal and aromatic plants according to Anna et al. (2001). Total genomic DNA was extracted using a modified CTAB method based on the protocol of Doyle and Doyle (1990). Young leaves were used for DNA extraction from each accession. Quality of DNA was tested by submerged horizontal agarose gel $(0.8 \%)$ electrophoresis and visualized with UV light.

Primers

A set of 16 primers was analyzed for RAPD and 8 primers for ISSR were used as listed in (Table $1 \& 2$ ).

\section{Polymerase chain reaction}

PCR amplifications were performed in a programmable thermocycler. Each sample was amplified in a reaction mixture containing $50 \mathrm{ng}$ genomic DNA, Taq polymerase 1 unit, $10 \times$ PCR buffer with $2.5 \mathrm{mM} \mathrm{MgCl} 2$ and $200 \mu \mathrm{M}$ of each dNTP mixture. Cycling parameters for ISSR were adjusted to $5 \mathrm{~min}$ at $94{ }^{\circ} \mathrm{C}$ for predenaturation, 39 cycles each of $1 \mathrm{~min}$ at $94{ }^{\circ} \mathrm{C}$ for denaturation, $1 \mathrm{~min}$ for annealing at 45/50/55 ${ }^{\circ} \mathrm{C}, 2 \mathrm{~min}$ at $72{ }^{\circ} \mathrm{C}$ for extension and a final extension at $72{ }^{\circ} \mathrm{C}$ for $5 \mathrm{~min}$. For RAPD marker analysis, the PCR reaction mix and program profile were similar to ISSR markers analysis except the annealing temperature which was adjusted to $37^{\circ} \mathrm{C}$. After cooling to $4{ }^{\circ} \mathrm{C}$, amplified products were stored at $-20{ }^{\circ} \mathrm{C}$ until electrophoresis. Amplified products were separated on $1.5 \%$ agarose gel in $1 \times$ TAE buffer with $1 \mathrm{~Kb}$ plus ladder (Fermentas) to determine the size of amplified DNA fragments. Gels were run for $4 \mathrm{~h}$ at $65 \mathrm{~V}$, stained with ethidium bromide and documented with gel documentation system.

\section{Data analysis}

The bands were scored for presence (1) or absence (0) and each band was regarded as locus. Data analysis Marker index for RAPD and ISSR markers was calculated in order to characterize the capacity of each primer to detect polymorphic loci among the genotypes. The data obtained by scoring the RAPD and ISSR profiles with different primers individually as well as collectively were subjected to the construction of similarity matrix using Jaccard's (Jaccard, 1908) coefficients. The similarity values were used for cluster analysis. Data analysis was done using NTSYSpc software 2.02 (Rohlf, 2000).

\section{Results And Discussion}

\section{Markers associated biochemical fingerprint based on SDS-PAGE}

Total proteins bands were illustrated in Figure (1, A and B). It gave proteins products from seeds and leaves of the two types of $C$. cartilaginea with five plants replications and $C$. spinosa with three plants replications. The proteins products with molecular sizes ranged from 12 to $70 \mathrm{kDa}$ in seeds while, molecular sizes ranged from 2 to $95 \mathrm{kDa}$ in leaves. The positive common bands were 70, 35, 22 and $18 \mathrm{kDa}$ in seeds but in leaves there were 35 and $25 \mathrm{kDa}$. The bands 30, 25 and 12 were positive unique bands, which found in $C$. cartilaginea and were the same negative bands were found in $C$. spinosa. The band $45 \mathrm{kDa}$ was the positive unique band, which was found in $C$. spinosa and was the same negative unique band, which found in $C$. cartilaginea in seeds. On the other hand, in leaves the bands75, 58, 15 and $5 \mathrm{kDa}$ were positive unique bands, which was found only in $C$. cartilaginea_and were the same negative bands, which found in $C$. spinosa. The bands $95,85,65,40,30,10$ and $2 \mathrm{kDa}$ were the positive unique bands, which were found in $C$. spinosa and were the same negative unique bands, which found in $C$. cartilaginea.

\section{Cluster analysis of Capparis species based on SDS-PAGE}

SDS-PAGE based on coefficients of genetic similarity among the ten DNA samples represented (Table 3). The strongest relationship scored between genotypes C.cartilaginea (3) and C.Cartilaginea (4) about $95 \%$ while genotypes $C$. cartilaginea (1) and $C$.spinosa (8) were shown similarity $62 \%$, dendrogram was constructed 
using UPGMA clustering to show the relationships among and between species a shown in figure (2). Results of this phylogenetic dendrogram indicated two clusters, the first one included all genotypes of C. spinosa (samples 8, 10, 6 and 7), while the second cluster included all genotypes of $C$. cartilagenea (samples 5, 9, 1, 3, 4 and 2). In general the SDS-PAGE was efficient in discriminating among the two Capparis sp. under investigation also it was helpful in characterization of genotypes within the same species.

\section{Markers associated molecular genetic fingerprints RAPD analysis}

The RAPD analysis was carried out using decamer primers of different series of OPERON Technologies $^{\circledR}$ for DNA amplifications through PCR, out of which only 16 primers responded to all the accessions of Capparis sp. under investigation based DNA analysis of eight plants as five replications plants from $C$. cartilaginea and three plants from $C$. spinosa. All primers used in the present study resulted in the appearance of PCR products with varied band numbers as shown in (Figure 3 and Table 4). A total of 188 DNA bands were detected across the sixteen random primers, 172 of them were polymorphic (about 91\%), (Table 4). Primers OP-A20, OP-O01 and OP-Z09 yielded the highest (100\%) polymorphism across the studied genotypes and primer OP-O13 was lowest $80 \%$ polymorphism The differences in number of amplified fragments and percent polymorphic fragments between $C$. cartilaginea and $C$. spinosa species is due to the difference in number of plants (Table 4 ).

\section{Capparis sp. positive specific markers based on RAPD-PCR}

The specific markers for two Capparis $s p$. generated (between and within) based on RAPD-PCR analysis are shown in (Tables 5). As high as total 42 positive (11 RAPD-PCR positive markers in C.cartilaginea and 31 in $C$. spinosa) out of the 188 bands (about 22\%) were found to be useful as species - specific markers, which present in all genotypes for the one species and absent in all genotypes for other species. The results of the present study revealed that the polymorphism detected by the RAPD assay (91\%) was higher than the polymorphism detected by ISSR assay (89\%).

\section{ISSR fingerprinting}

ISSR analysis were performed on the eight DNA samples representing the two studied species using eight ISSR primers composed of short tandom repeat sequences with or without anchor. (Figure 4 and Table 6) illustrating the ISSR of the two Capparis sp.. A total of 76 amplicons were generated by the tested primers. ISSR primers HB08 and 814 exhibited the height number of fragments (15 and 11 amplicons, respectively). While the lowest amplicon numbers were scored by primers $844 \mathrm{~A}$ with 5 amplicons.

The total number of polymorphic bands was 78 with an average of 8.5 polymorphic amplicons / primer. This represents a level of polymorphism about of $89 \%$ (Table 6). The number of polymorphic markers varied among the different primers. Primers 17898A and HB15 generated 9 polymorphic bands for each with $100 \%$ polymorphism. While primers 814 and HB10 showed low level of polymorphism (81 and $80 \%$, respectively).

\section{Capparis species-positive specific markers based on ISSR-PCR:}

The specific markers for two Capparis $s p$. generated (between and within) based on ISSR-PCR analysis are shown in (Table 7). As high as 19 ISSR-PCR positive markers out of the 76 bands (about 25\%) were found to be useful as species-positive specific markers, which presented in all genotypes for one species and absent in all genotypes for the other species. The largest number of ISSR-PCR species-specific markers was generated by primer HB10 (6 markers) followed by primers 814 and HB15 (3 markers for each,). On the other hand, the least number of ISSR-PCR species-positive specific markers was generated by primers 17898A and HB9 (one marker).

The ISSR technology is sensitive to considerable levels of genetic variation, providing a very useful molecular tool for studying population genetics on a wide range of plant species, as well as for identifying species, cultivars, or population of the same species (Wang et al., 2009). ISSR analysis is a PCR-based method with advantages of low-cost and high-efficiency as compared with other DNA genotyping techniques. The results indicated that ISSR markers have been successfully utilized for assessing the genetic diversity and revealed a remarkable molecular discrimination between the two Capparis sp. under study. Moreover, (Galvan et al. 2003) concluded that ISSR would be a better tool than RAPD for phylogenetic studies. (Nagaoka and Ogihara 1997) have also reported that the ISSR primers produced several times more information than RAPD markers. The number of potential ISSR markers depends on the frequency of microsatellites, which changes with species (Depeiger et al., 1995), So that the potential for integrating ISSR-PCR into plant improvement program is enormous and their applications in different crop species are sufficiently reviewed (Reddy $\boldsymbol{e t}$ al., 2002). 


\section{Combined cluster analysis of Capparis species based on RAPD and ISSR-PCR:}

Phylogenetic relationship was generated using RAPD and ISSR markers. The similarity matrix was tabulated in Table (8) and the phylogenetic dendrogram was illustrated in Figure (5). The analysis revealed that the strongest relationship (95\%) was between two pairs of genotypes (C.cartiliginea $2 \&$ C. cartiliginea 3), while genotypes $C$. cartiliginea (3) and $C$. spinosa (8) were shown to be medium in genetic relation (76\%).

The dendrogram tree among the Capparis genotypes for polymorphisms detected according to RAPD and ISSR is shown in Figure (5). Results of this phylogenetic dendrogram indicated two clusters, the first one included $C$. cartilaginea genotypes (2, 3 and 1), while the second cluster included genotypes of $C$. cartilaginea and C. spinosa species $(6,7,4,5$ and 8$)$, which was divided into two sub cluster, the first one contained two C. spinosa genotypes (6 and 7), while the other sub cluster contain tow C. cartilaginea (4 and 5).

Generally, the results RAPD and ISSR PCR techniques have a sufficient value in determining Capparis species/genotype-specific markers and Capparis taxonomy.

Considering the data mentioned before as a molecular fingerprinting for the eight studied of Capparis genotypes, it could be concluded that the employment of RAPD and ISSR banding patterns variation as tools for the detection of similarities and dissimilarities of the studied Capparis genotypes are inconsiderable useful tools. The same conclusion was obtained by several authors (EL-Fiky et al., 2002).

\section{Conclusion}

As a conclusion, the current results confirm C. cartilaginea and C. spinosa, wild and cultivated populations differ from each other because wild populations usually originate from composites with higher genetic variability and, most of the time, it is difficult to allocate wild composites to well-defined heterotic groups by phenotypic evaluation. Due to this uniqueness, molecular markers have been very useful in genetic evaluations and assignment of Capparis plants to heterotic groups. Discussion Similar levels of genetic distance estimates were obtained using the RAPD and ISSR markers.

Comparison of the genetic distances generated by different molecular markers in diversity studies have been reported by several authors (Duarte $\boldsymbol{e t}$ al., 1999 and Zoghlami $\boldsymbol{e t}$ al., 2001) compared different molecular markers to assess the genetic similarities between wild species and found great differences in the RAPD similarity clustering pattern. The results obtained in our study showed high agreement between RAPD and ISSR genetic distance estimates, such estimates having also been highly correlated in other studies (Gilbert et al., 1999 and Alexander, 2002). Indeed, we found that the RAPD and ISSR markers produced sufficient numbers of polymorphic bands to produce reliable genetic distance estimates with high correlations between these two marker systems, the similarity between the results being explainable by the fact that they are similar techniques based on complementary sequence changes. Our results indicate that, apart from the RAPD markers, the other DNA marker systems provided consistent information for diversity studies on medicinal plant populations and produced genetic distance estimates which were in good agreement.

The ISSR system appears to be the most robust marker assay in terms of the amount of polymorphism surveyed, although, in practice, it is still a very laborious technique. The ISSR markers were promising in terms of the polymorphism and information content revealed, but may involve some additional initial costs associated with primer development.

Our results suggest that RAPD markers are the best choice for the evaluation of diversity and assessing the genetic relationships between two Capparis sp. with high accuracy. RAPD also correlates highly with results obtained using the ISSR system and is a fast and reliable system capable of supporting a multiplex approach not requiring previous knowledge of DNA sequencing.

The conservation of wild plants as genetic resources requires an understanding the ways of genetic diversity maintained in their population. Gene conservation strategies of this species should be designed using in part the information obtained from this study. The fingerprints were useful not only for investigation genetic variability but also for further characterizing the wild Capparis sp. by detecting inter and intra-specific polymorphism constructing dendrogram defining the phylogenetic relationships among these species and identifying molecular markers for the construction of genetic linkage maps. Furthermore, unique markers distinguished particular species were successfully identified indicating the PCR based techniques can have great relevance for taxonomic studies. Conservationist may use the information of the present study to make effective decisions regarding the global protection and management of Capparis sp. in Egypt. 


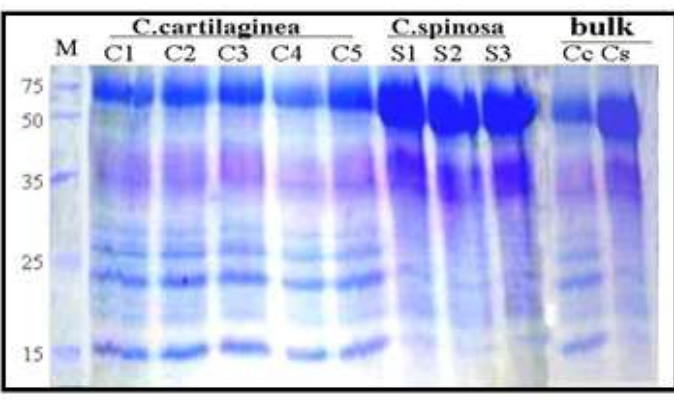

A

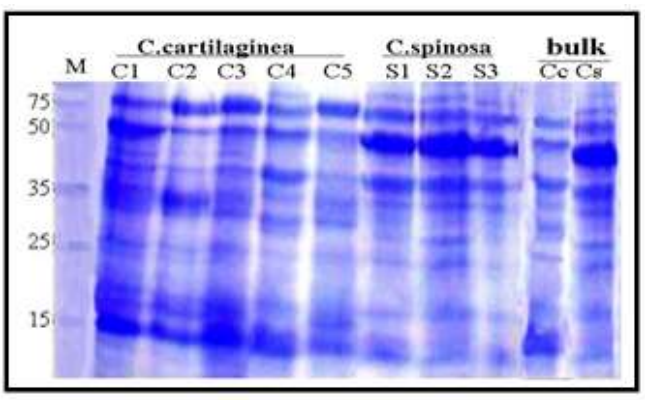

B

Figure (1): Individual and bulk total proteins polymorphism of the C. cartilaginea and C. spinosa seeds A and leaves B. Using SDS-PAGE.

Table (1): List of 16 RAPD primers and their nucleotide sequence

\begin{tabular}{|l|l|l|l|}
\hline primer & Sequence 5'to 3' & primer & Sequence 5'to 3' \\
\hline OP A4 & 5- AATCGGGCTG-3 & OP B10 & 5-CTGCTGGGAC-3 \\
\hline OP A5 & 5-AGGGGTCTTG-3 & OP B15 & 5-GGAGGGTGTT-3 \\
\hline OP A10 & 5-GTGATCGCAG-3 & OP B20 & 5-GGACCCTTAC-3 \\
\hline OP A15 & 5-TTCCGAACCC-3 & OP O1 & 5-GGCACGTAAG-3 \\
\hline OP A19 & 5-CAAACGTCGG-3 & OP O8 & 5-CCTCCAGTGT-3 \\
\hline OP A20 & 5-GTTGCGATCC-3 & OP O13 & 5-GTCAGAGTCC-3 \\
\hline OP B1 & 5-GTTTCGCTCC-3 & OP Z9 & 5'-CACCCCAGTC-3' \\
\hline OP B5 & 5-TGCGCCCTTC-3 & OP Z16 & 5-TCCCCATCAC-3 \\
\hline
\end{tabular}

Table (2): List of 8 ISSR primers and their nucleotide sequence

\begin{tabular}{|l|l|}
\hline primer & Sequence 5'to 3' \\
\hline HB08 & (GA)6 GG \\
\hline HB09 & (GT)6GG \\
\hline HB10 & (GA)6 CC \\
\hline HB11 & (GT)6 CC \\
\hline HB15 & (GTG)3 GC \\
\hline 17898A & (CA)6AC \\
\hline 814 & (CT)8A \\
\hline 844A & (CT)8AC \\
\hline
\end{tabular}

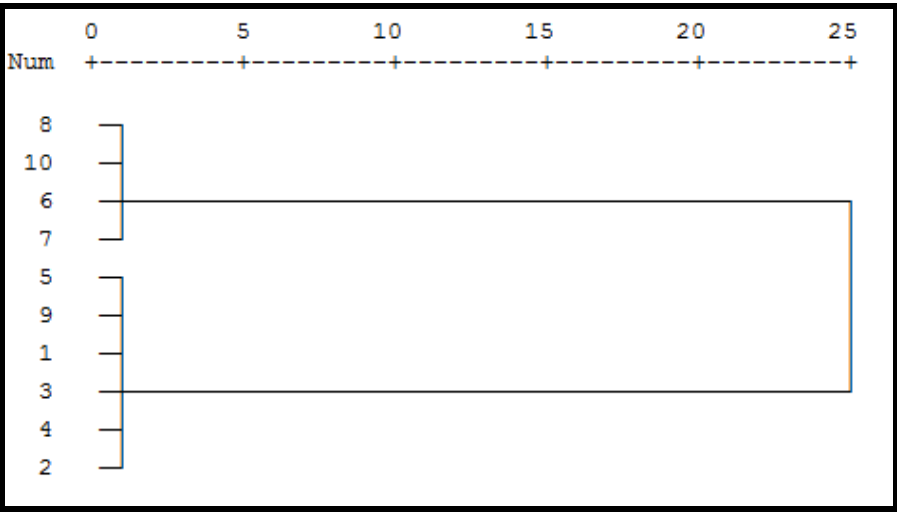

Figure (2): Dendrogram of the two Capparis sp. Based on SDS-PAGE.

Table (3): Similarity matrix of the two Capparis sp. based on SDS-PAGE.

\begin{tabular}{|c|c|c|c|c|c|c|c|c|c|c|}
\hline Capparis sp. & $\mathbf{1}$ & $\mathbf{2}$ & $\mathbf{3}$ & $\mathbf{4}$ & $\mathbf{5}$ & $\mathbf{6}$ & $\mathbf{7}$ & $\mathbf{8}$ & $\mathbf{9}$ & $\mathbf{1 0}$ \\
\hline $\mathbf{1}$ & 100 & & & & & & & & & \\
\hline $\mathbf{2}$ & 76 & 100 & & & & & & & & \\
\hline $\mathbf{3}$ & 85 & 84 & 100 & & & & & & & \\
\hline $\mathbf{4}$ & 78 & 90 & 95 & 100 & & & & & & \\
\hline $\mathbf{5}$ & 75 & 81 & 84 & 79 & 100 & & & & & \\
\hline $\mathbf{6}$ & 65 & 75 & 72 & 75 & 80 & 100 & & & & \\
\hline $\mathbf{7}$ & 63 & 73 & 74 & 77 & 81 & 91 & 100 & & & \\
\hline $\mathbf{8}$ & 62 & 71 & 77 & 79 & 79 & 89 & 92 & 100 & & \\
\hline $\mathbf{1 0}$ & 83 & 72 & 83 & 89 & 93 & 83 & 89 & 89 & 100 & \\
\hline
\end{tabular}

1, 2, 3, 4 and 5: C. cartilaginea 6,7 and 8: C. spinosa 9 and 10: Bulk 

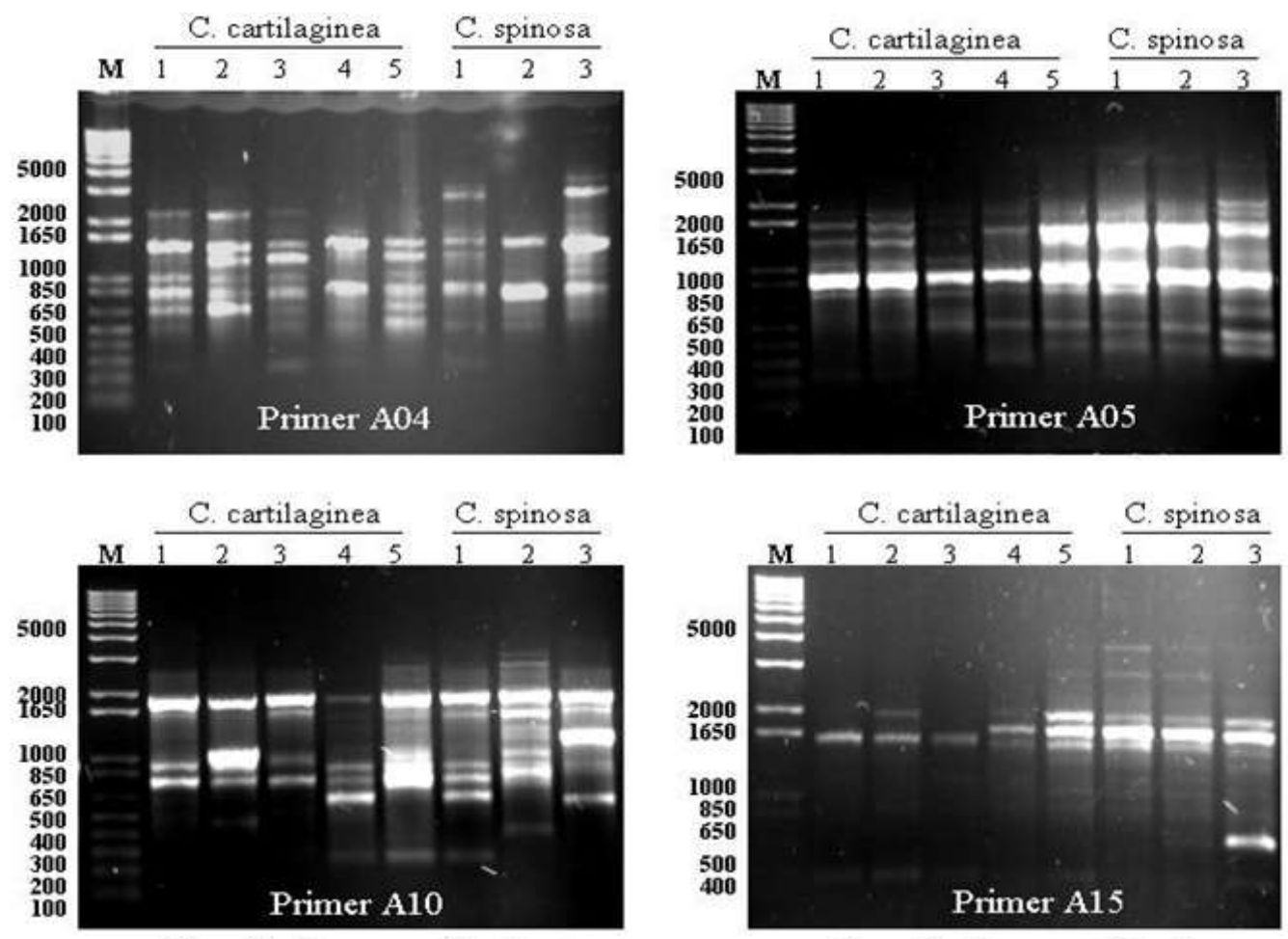

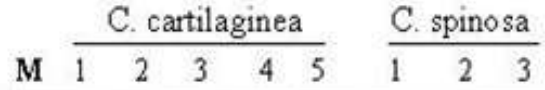
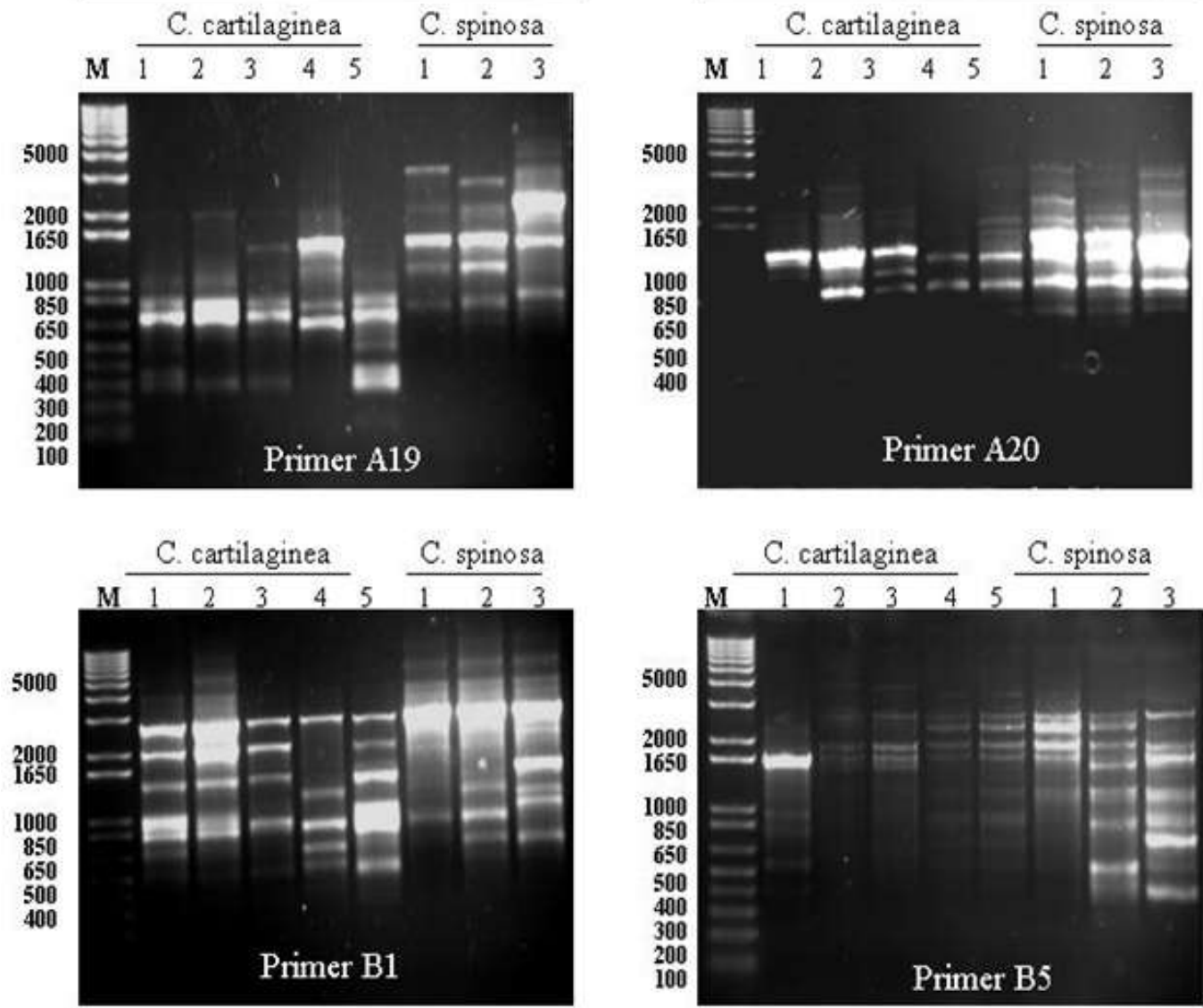

Figure (3): DNA polymorphism of the two Capparis sp. using RAPD-PCR with primers. 
Molecular Genetic Markers And Biochemical Detection Between Two Capparis Sp.
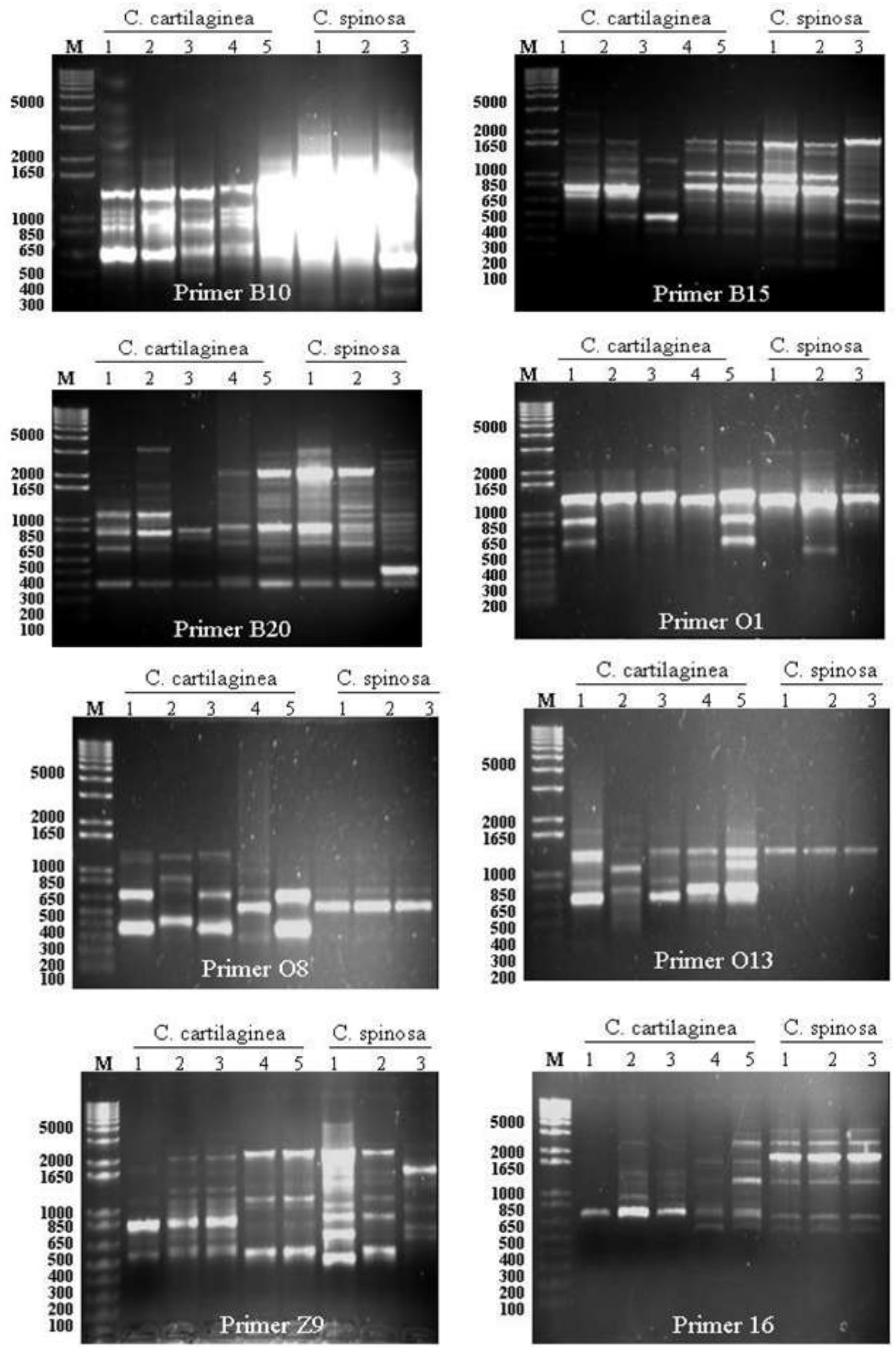

Figure (3): (cont') 
Molecular Genetic Markers And Biochemical Detection Between Two Capparis Sp.

\begin{tabular}{|c|c|c|c|c|c|c|c|c|c|c|c|c|c|c|c|c|c|c|c|}
\hline \multicolumn{20}{|c|}{ Table (4). Number of amplified frazments and specific markers for the two Cagparis sp, based on RAPD-PCR } \\
\hline & & & $\begin{array}{c}\mathrm{OpA}- \\
\mathrm{OH}\end{array}$ & $\begin{array}{c}\mathrm{OpA}- \\
05\end{array}$ & $\begin{array}{c}\text { OPA } \\
10\end{array}$ & $\begin{array}{c}\text { OpA } \\
15\end{array}$ & $\begin{array}{c}\text { OPA- } \\
19\end{array}$ & $\begin{array}{c}\mathrm{OPA} \\
20\end{array}$ & $\begin{array}{c}\mathrm{O}_{g \mathrm{~B}}- \\
01\end{array}$ & $\begin{array}{c}\text { OPB } \\
05\end{array}$ & $\begin{array}{c}\mathrm{Op}_{\mathrm{p}} \\
10\end{array}$ & $\begin{array}{c}\mathrm{OpB}_{\mathrm{p}}- \\
15\end{array}$ & $\begin{array}{c}\mathrm{Op}_{20} \\
20\end{array}$ & $\begin{array}{c}\mathrm{OpO} \text {. } \\
01\end{array}$ & $\begin{array}{c}\text { OpO- } \\
08\end{array}$ & $\begin{array}{c}\text { OPO } \\
13\end{array}$ & $\begin{array}{c}\text { OPZ - } \\
09\end{array}$ & $\begin{array}{c}\text { OPZ } \\
16\end{array}$ & total \\
\hline & \multicolumn{2}{|c|}{ TAF } & 12 & 15 & 15 & II & 12 & 12 & 13 & 12 & 14 & 12 & 16 & 10 & 7 & 5 & 10 & 10 & 188 \\
\hline & \multicolumn{2}{|c|}{$\mathrm{CB}$} & 2 & 1 & 1 & I & 1 & $\cdot$ & 1 & 1 & 1 & 1 & 1 & 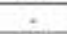 & 1 & I & - & 2 & 15 \\
\hline & \multicolumn{2}{|c|}{$\mathrm{PB}$} & 10 & 14 & 14 & 10 & II & 12 & 12 & II & 13 & II & 15 & 10 & 6 & 4 & 10 & 9 & 172 \\
\hline \multicolumn{20}{|c|}{ Capparts Cartilaginea } \\
\hline \multirow{10}{*}{ 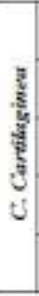 } & \multirow[t]{2}{*}{$\mathrm{Cl}$} & $\mathrm{AF}$ & 7 & 7 & 5 & 1 & 5 & 3 & 8 & 5 & 9 & 7 & 5 & 4 & 3 & 4 & 4 & 2 & 79 \\
\hline & & SM & - & 1 & 1 & . & . & . & 1 & 1 & 3 & 1 & - & . & - & 1 & 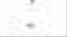 & - & 9 \\
\hline & \multirow[t]{2}{*}{$\mathrm{C} 2$} & $\mathrm{AF}$ & 6 & 7 & 6 & 3 & 5 & 5 & 9 & 4 & 4 & 6 & 9 & 3 & 4 & 4 & 8 & 6 & 89 \\
\hline & & SM & - & - & 1 & - & . & $i$ & - & - & - & 1 & - & - & 1 & - & 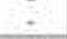 & - & 4 \\
\hline & \multirow[t]{2}{*}{$\mathrm{C} 3$} & AF & 8 & 5 & 5 & I & 5 & 5 & 6 & 4 & 5 & 5 & 4 & 3 & 3 & 3 & 8 & 6 & 76 \\
\hline & & SM & - & 2 & - & - & . & - & - & - & - & 1 & 1 & - & - & - & - & - & 4 \\
\hline & \multirow[t]{2}{*}{$\mathrm{CH}$} & AF & 6 & 5 & 5 & 2 & 5 & 2 & 5 & 7 & 6 & 6 & 6 & 1 & 4 & 3 & 4 & 5 & 72 \\
\hline & & SM & 1 & 1 & 1 & - & 1 & . & 1 & - & - & - & - & - & 2 & - & - & - & 7 \\
\hline & \multirow[t]{2}{*}{ CS } & $\mathrm{AF}$ & 6 & 6 & 8 & 6 & 6 & 8 & 5 & 7 & 4 & 6 & 10 & 4 & 3 & 3 & 4 & 8 & 94 \\
\hline & & SM & . & 1 & 2 & 2 & 2 & 3 & . &. & $=$ & . & 2 & 1 & . & . & . & 1 & 14 \\
\hline \multicolumn{20}{|c|}{ Capperis Spinosa } \\
\hline \multirow{6}{*}{$\begin{array}{l}\frac{2}{2} \\
\frac{1}{2} \\
5 \\
\text { t5 }\end{array}$} & \multirow[t]{2}{*}{ St } & AF & 7 & 6 & 7 & 8 & 5 & 7 & 5 & 6 & 6 & 6 & 7 & 3 & 2 & 2 & 5 & 6 & 88 \\
\hline & & SM & 3 & - & 2 & 1 & . & . & - & - & - & . & 1 & 1 & - & 1. & - & - & 9 \\
\hline & \multirow[t]{2}{*}{52} & $\mathrm{AF}$ & 4 & 5 & 10 & 9 & 6 & 8 & 7 & 7 & 7 & 6 & 10 & 4 & 2 & 1 & 6 & 7 & 99 \\
\hline & & $\mathrm{SM}$ & 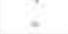 & . & 6 & $i$ & 1 & 2 & . & 1 & . & 1 & 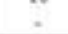 & 2 & . & . & . & 1 & 15 . \\
\hline & \multirow[t]{2}{*}{$\$ 3$} & AF & 6 & 9 & 6 & 5 & 6 & 5 & 8 & 10 & $T$ & 7 & 12 & 2 & 2 & 2 & 5 & 6 & 98 \\
\hline & & $\mathrm{SM}$ & 2 & 5 &. & 1 & 1 & 2 & 3 & 2 & 2 & 2 & 4 & 2 & 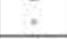 & 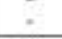 & 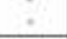 & 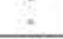 & 26 \\
\hline \multirow{2}{*}{\multicolumn{2}{|c|}{ 륭 }} & AF & 50 & 50 & 52 & 35 & 43 & 43 & 53 & 50 & 48 & 49 & 63 & 24 & 23 & 22 & 4 & 46 & 695 \\
\hline & & $\mathrm{SM}$ & 6 & 10 & 13 & 5 & 5 & 8 & 5 & 4 & 5 & 6 & 8 & 6 & 3 & 2 & - & 2 & 88 \\
\hline
\end{tabular}

TAF: Total amplified fragments

CB: Common bands

PB: Polymorphic bands

Table (5): Positive specific markers Capparis sp. resulting from RAPD-PCR and their primers

\begin{tabular}{|c|c|}
\hline \multicolumn{2}{|r|}{ Positive Markers } \\
\hline Capparis cartilaginea & Capparis spinosa \\
\hline $\begin{array}{l}\text { 600bp(A4), } 615 \mathrm{bp}(\mathrm{A} 5), 395 \mathrm{bp}(\mathrm{A} 5), \\
705 \mathrm{bp}((\mathrm{A} 10),\end{array}$ & $\begin{array}{lllll}1645 \mathrm{bp}(\mathrm{A} 4), & 136 \mathrm{bp}(\mathrm{A} 4), & 1735 \mathrm{bp}(\mathrm{A} 10), & 860 \mathrm{bp}(\mathrm{A} 10), & 220 \mathrm{bp}(\mathrm{A} 15), \\
1930 \mathrm{bp}(\mathrm{A} 15), & 2170 \mathrm{bp}(\mathrm{A} 19), & 1435 \mathrm{bp}(\mathrm{A} 19), & 760 \mathrm{bp}(\mathrm{A} 20), & 530 \mathrm{bp}(\mathrm{A} 20),\end{array}$ \\
\hline $\begin{array}{ll}\text { 1155bp(A20), } & \text { 1780bp(B5), } \\
665 \mathrm{bp}(\mathrm{O} 13), & 1335 \mathrm{bp}(\mathrm{Z} 9), \\
910 \mathrm{bp}(\mathrm{Z} 9), 575 \mathrm{bp}(\mathrm{Z9}) & \end{array}$ & 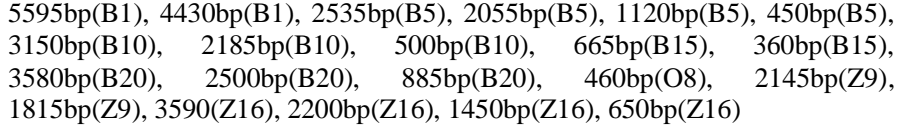 \\
\hline
\end{tabular}
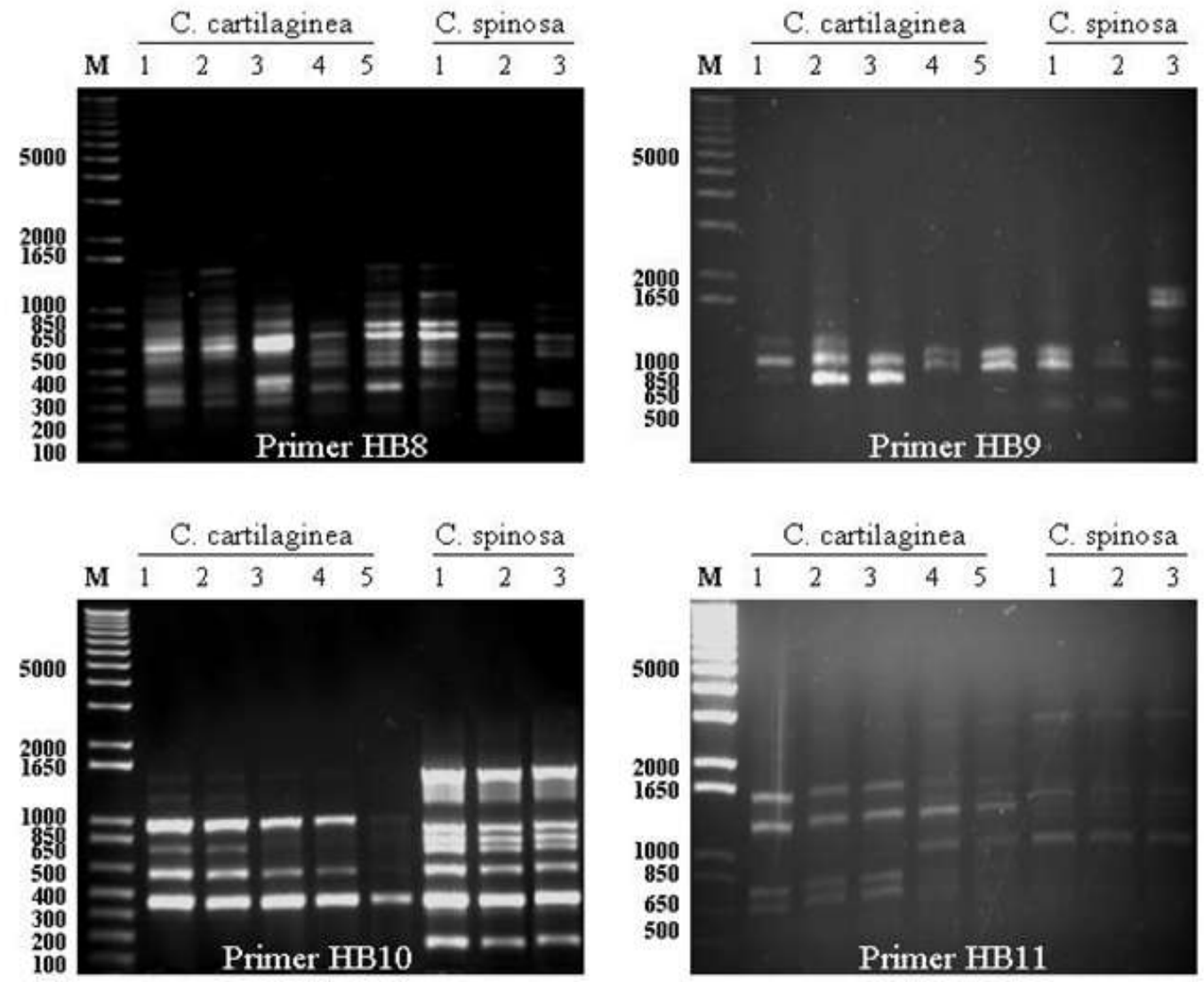
Molecular Genetic Markers And Biochemical Detection Between Two Capparis Sp.
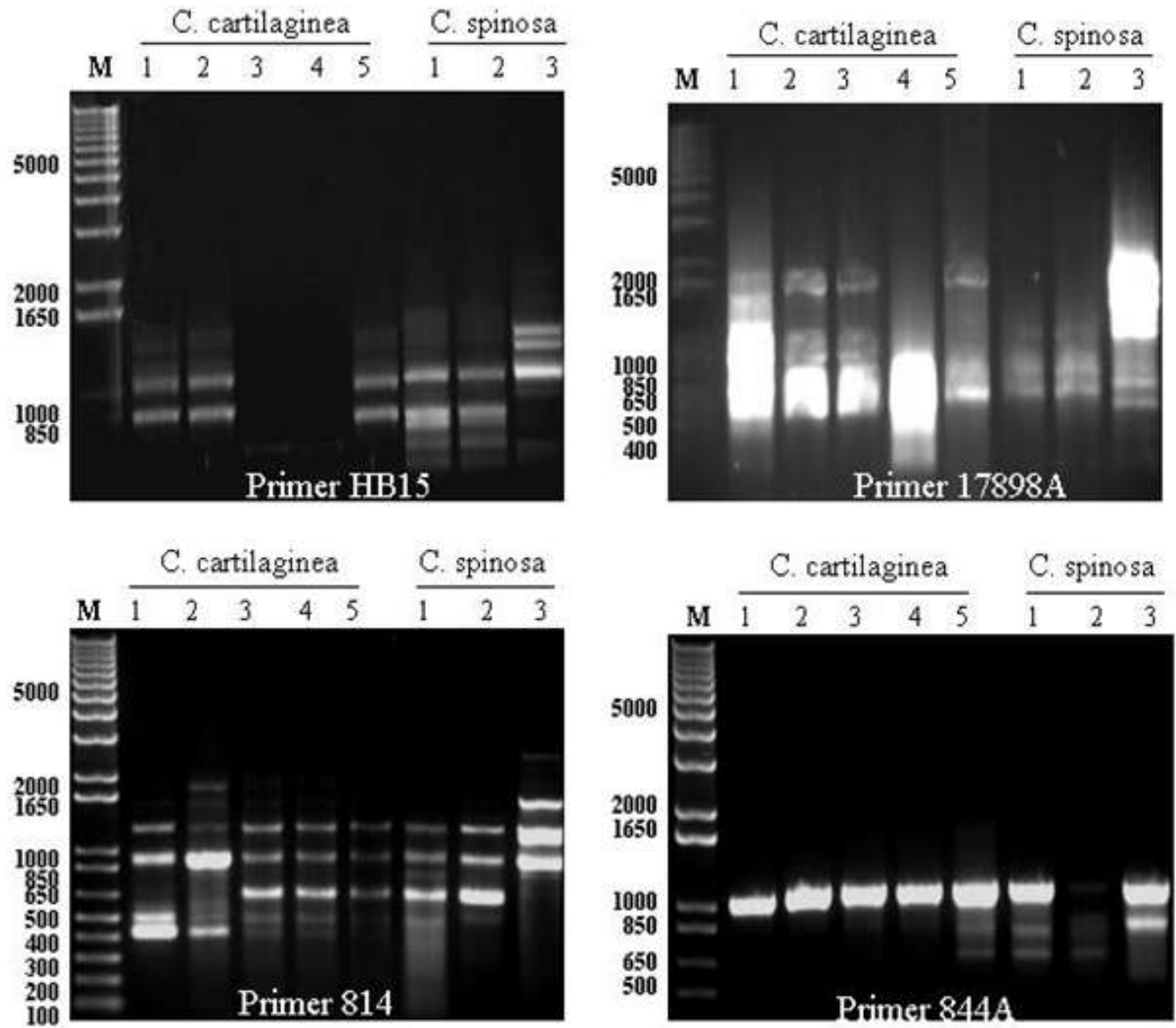

Figure (4): DNA polymorphism of the two Capparis $s p$. using ISSR primers

Table (6): Number of amplified fragments and specific markers for the two Capparis $s p$.

\begin{tabular}{|c|c|c|c|c|c|c|c|c|c|c|c|}
\hline \multicolumn{12}{|c|}{ Specific primers } \\
\hline & & & 17898A & 814 & 844A & HB10 & HB11 & HB15 & HB8 & HB9 & Total \\
\hline & & TAF & 9 & 11 & 5 & 10 & 8 & 9 & 15 & 9 & 76 \\
\hline & & $\mathrm{CB}$ & - & 2 & 1 & 2 & 1 & - & 1 & 1 & 8 \\
\hline & & PB & 9 & 9 & 4 & 8 & 7 & 9 & 14 & 8 & 68 \\
\hline \multicolumn{12}{|c|}{ Capparis cartilaginea } \\
\hline \multirow{10}{*}{ 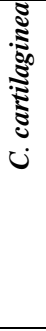 } & 1 & $\mathrm{AF}$ & 3 & 5 & 2 & 6 & 3 & 3 & 10 & 3 & 35 \\
\hline & & SM & 1 & - & 1 & - & 1 & 1 & - & - & 4 \\
\hline & 2 & $\mathrm{AF}$ & 4 & 7 & 2 & 6 & 3 & 3 & 9 & 5 & 39 \\
\hline & & SM & 1 & 1 & - & - & - & - & - & 1 & 3 \\
\hline & 3 & $\mathrm{AF}$ & 3 & 7 & 2 & 5 & 5 & 1 & 7 & 2 & 32 \\
\hline & & SM & - & - & - & - & - & - & - & - & - \\
\hline & 4 & $\mathrm{AF}$ & 2 & 7 & 2 & 5 & 6 & 1 & 6 & 2 & 31 \\
\hline & & SM & 2 & - & - & - & - & - & - & 1 & 3 \\
\hline & 5 & $\mathrm{AF}$ & 2 & 5 & 2 & 5 & 4 & 3 & 10 & 5 & 36 \\
\hline & & SM & - & - & - & - & 1 & - & 4 & 2 & 7 \\
\hline \multicolumn{12}{|c|}{ Capparis spinosa } \\
\hline \multirow{6}{*}{ 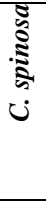 } & 1 & $\mathrm{AF}$ & 2 & 5 & 3 & 8 & 3 & 6 & 9 & 4 & 40 \\
\hline & & SM & - & 1 & - & - & - & 1 & 1 & - & 3 \\
\hline & 2 & $\mathrm{AF}$ & 3 & 5 & 3 & 8 & 3 & 5 & 7 & 5 & 39 \\
\hline & & SM & - & 1 & - & - & - & - & 1 & 1 & 3 \\
\hline & 3 & $\mathrm{AF}$ & 4 & 5 & 3 & 8 & 3 & 7 & 8 & 5 & 43 \\
\hline & & SM & 2 & 2 & 1 & - & - & 2 & 3 & 3 & 13 \\
\hline & & $\mathrm{AF}$ & 23 & 46 & 19 & 51 & 30 & 29 & 66 & 31 & 295 \\
\hline$\stackrel{0}{0}$ & & SM & 6 & 5 & 2 & - & 2 & 4 & 9 & 8 & 36 \\
\hline
\end{tabular}

TAF: Total amplified fragments

CB: Common bands

PB: Polymorphic bands 
Molecular Genetic Markers And Biochemical Detection Between Two Capparis Sp.

Table (7): Positive specific markers Capparis sp. resulting from ISSR-PCR and their primers

\begin{tabular}{|c|lcr|}
\hline \multicolumn{4}{|c|}{ Positive Markers } \\
\hline Capparis cartilaginea & \multicolumn{3}{c|}{ Capparis spinosa } \\
\hline $420 \mathrm{bp}(814), 360 \mathrm{bp}(814)$ & $1100 \mathrm{bp}(17898 \mathrm{~A})$, & $560 \mathrm{bp}(814)$, & $855 \mathrm{bp}(844 \mathrm{~A})$, \\
& $1675 \mathrm{bp}(\mathrm{HB} 10)$, & $1305 \mathrm{bp}(\mathrm{HB} 10)$, & $840 \mathrm{bp}(\mathrm{HB} 10)$, \\
& $825 \mathrm{bp}(\mathrm{HB} 10)$, & $745 \mathrm{bp}(\mathrm{HB} 10)$, & $270 \mathrm{bp}(\mathrm{HB} 10)$, \\
& $3430 \mathrm{bp}(\mathrm{HB} 11)$, & $1145 \mathrm{bp}(\mathrm{HB} 11)$, & $1100 \mathrm{bp}(\mathrm{HB} 15)$, \\
& $795 \mathrm{bp}(\mathrm{HB} 15)$, & $620 \mathrm{bp}(\mathrm{HB} 15)$, & $655 \mathrm{bp}(\mathrm{HB} 8)$, \\
& 520bp(HB8), & $1355 \mathrm{bp}(\mathrm{HB} 9)$ & \\
\hline
\end{tabular}

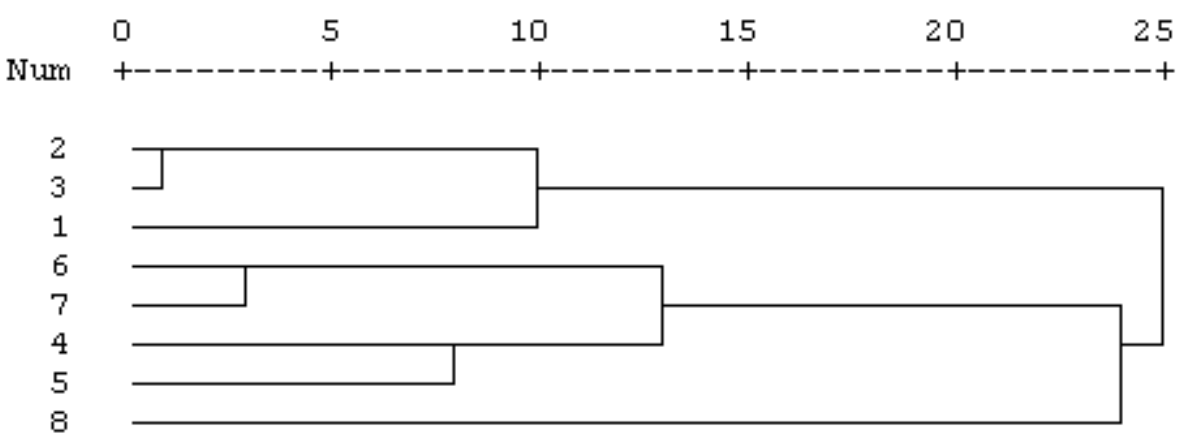

Figure (5): Dendrogram of the two Capparis sp. based on RAPD and ISSR.

Table (8): Similarity matrix of the two Capparis sp. based on RAPD and ISSR.

\begin{tabular}{|c|c|c|c|c|c|c|c|c|}
\hline Capparis $\boldsymbol{s p}$. & $\mathbf{1}$ & $\mathbf{2}$ & $\mathbf{3}$ & $\mathbf{4}$ & $\mathbf{5}$ & $\mathbf{6}$ & $\mathbf{7}$ & $\mathbf{8}$ \\
\hline $\mathbf{1}$ & 100 & & & & & & & \\
\hline $\mathbf{2}$ & 85 & 100 & & & & & & \\
\hline $\mathbf{3}$ & 86 & 95 & 100 & & & & & \\
\hline $\mathbf{4}$ & 79 & 89 & 79 & 100 & & & & \\
\hline $\mathbf{5}$ & 83 & 86 & 82 & 94 & 100 & & & \\
\hline $\mathbf{6}$ & 86 & 87 & 88 & 90 & 89 & 100 & & \\
\hline $\mathbf{7}$ & 84 & 81 & 85 & 92 & 90 & 93 & 100 & \\
\hline $\mathbf{8}$ & 80 & 79 & 76 & 90 & 89 & 89 & 90 & 100 \\
\hline
\end{tabular}

1, 2, 3, 4 and 5: C. cartilaginea

6, 7 and 8: $C$. spinosa

References

[1]. Abdel-Mawgood, A. L., Assaeed, A. M. \& Al-Abdallatif, T. I.(2006). Application of RAPD technique for the conservation of an isolated population of Capparis decidua. Alexandria J. Agric. Res. 51: 171-177.

[2]. Abou Hadid A, Kamal B, Jabarine A, Kader A (2004). Proposal for Expan-ding the Crop Mandate of ICARDA to Include Horticultural Crops, ICARDA, Syria, 38 pp.

[3]. Alexander, A. J. (2002). Genetic diversity of populations of Astragalus oniciformis using Inter-simple sequence repeat (ISSR) markers. Master of Science in Botany and Plant Pathology, Oregon State University.

[4]. Anna M.P., Hirsikorpi M, Kämäräinen T, Jaakola L, Hohrola A (2001). DNA isolation methods for medicinal and aromatic plants. Plant Mol.Biol. Rep., 19: 273a-f.

[5]. Boulos L. (2009). Flora of Egypt. Four volumes. Cairo: Al-Hadara Publishing, Egypt.

[6]. Doyle J.J., Doyle J.L., (1990). Isolation of plant DNA from fresh tissue. Focus, 12: 13 -15.

[7]. Duarte, J.M., J.B.D. Santos, and L.C. Melo (1999). Genetic divergence among common bean cultivars from different races based on RAPD markers. Genetics and Molecular Biology, 22: 419-426.

[8]. EI-Fiky, Z. A., Mona H. Hassein., E. M. Mohamed and H. A. Hussein (2002). Biochemical and molecular genetic studies using SDS-protein, isozymes and RAPD-PCR in some common bean (Phaseolus vulgaris L.) cultivars. Arab J. Biotech. 5: $249-262$.

[9]. Gilbert, J. E., R. V. Lewis, M. j. Wilkinson and P. D. Caligari (1999). Developing an appropriate strategy to assess genetic variability in plant germplasm collections. Theor. and Appl Genet., 98: 1125-1131.

[10]. Gunther R. (1959). The Greek Herbal of Dioscorides. New York: Hafner Publishing Co. p. 215.

[11]. IPGRI (2001). Enhancing the Contribution of Neglected and Underutilized Spe- cies to Food Security, and to Incomes of the Rural Poor. Available online: http://www.ipgri.cgiar.org.

[12]. Jaccard, P. (1908). Nouvelles recherches sur la distribution florale. Bull Soc. Vaudoise Sci. Nat. 44:223-270

[13]. Laemmli, U. K. (1970). Cleavage of structural proteins during the assembly of the head of bacteriophage T4. Nature, 227: 680-685.

[14]. Li, Y. (2005). Study on relationships of the local varieties of alfalfa (Medicago sativa L.) in China seed storage protein markers Acta Prataculturae Slnica, 8: 31-41.

[15]. Nagaoka, T. and Y. Ogihara (1997). Applicability of inter-simple sequence repeat polymorphisms in wheat for use as DNA markers in comparison to RFLP and RAPD markers. Theoretical and applied genetics 94: 597-602.

[16]. Reddy MP, Sarla N, Siddiq EA (2002). Inter simple sequence repeat (ISSR) polymorphism and its application in plant breeding. Euphytica 128: 9-17.

[17]. Rohlf F.J. (2000). NTSYS-pc, Numerical Taxonomy and Multivariate Analysis System. Version 2.11. New York, Exeter, Setauket.

[18]. Shahina A.G. (1994). Capparaceae. In: Boca Raton., editor. Handbook of Arabian Medicinal Plants. USA: CRC Press, Inc. p. 73.

[19]. Täckholm V (1974). Student's Flora of Egypt. 2nd. Beirut: Cairo University Cooperative Printing Company;. p. 162. 
[20]. Vidaeus L (2002). Jordan, Conservation of Medicinal and Herbal Plants Project. The World Bank. Available online: http://www.gefweb.org

[21]. Wang XM, Ren Y (2009). Rheum tanguticum, an endangered medicinal

[22]. plant endemic to China. J. Med. Plants Res. 3(13): 1195-1203.

[23]. Waugh, R., W. Powell, (1992). Using RAPD markers for crop improvement. Trends Biotech, 10: 186-191.

[24]. Williams, J.G.K., M.K. Hanafey, J.A. Rafalski and S.V. Tingey (1993). Genetic analysis using random amplified polymorphic DNA markers. Meth. Enzymol. 218: 704-740.

[25]. Zoghlami, N., A. Mliki and A. Ghorbel (2001). Evaluation of genetic diversity among Tunisian grapevines by RAPD markers. Vitis, 40: 31-37. 